Check for updates

Cite this: RSC Adv., 2019, 9, 6919

\title{
Co-production of solvents and organic acids in butanol fermentation by Clostridium acetobutylicum in the presence of lignin-derived phenolics
}

\author{
Hongzhen Luo, (DD *a Panli Zheng, ${ }^{a}$ Fang Xie, ${ }^{a}$ Rongling Yang, ${ }^{a}$ Lina Liu, ${ }^{a}$ Shuo Han, (D) \\ Yuping Zhao a and Muhammad Bilal ${ }^{\mathrm{a}}$
}

Co-production of solvents (butanol, acetone, and ethanol) and organic acids (butyrate and acetate) by Clostridium acetobutylicum using lignocellulosic biomass as a substrate could further enlarge the application scope of butanol fermentation. This is mainly because solvents and organic acids could be used for production of fine chemicals such as butyl butyrate, butyl oleate, etc. However, many phenolic fermentation inhibitors are formed during the pretreatment process because of lignin degradation. The present study investigated the effects of five typical lignin-derived phenolics on the biosynthesis of solvents and organic acids in C. acetobutylicum ATCC 824. Results obtained in $100 \mathrm{~mL}$ anaerobic bottles indicated that butanol concentration was enhanced from $10.29 \mathrm{~g} \mathrm{~L}^{-1}$ to $11.36 \mathrm{~g} \mathrm{~L}^{-1}$ by the addition of $0.1 \mathrm{~g} \mathrm{~L}^{-1}$ vanillin. Subsequently, a $\mathrm{pH}$-control strategy was proposed in a $5 \mathrm{~L}$ anaerobic fermenter to alleviate the "acid crash" phenomenon and improve butanol fermentation performance, simultaneously. Notably, organic acid concentration was enhanced from $6.38 \mathrm{~g} \mathrm{~L}^{-1}$ (control) to a high level of 9.21$12.57 \mathrm{~g} \mathrm{~L}^{-1}$ with vanillin or/and vanillic acid addition $\left(0.2 \mathrm{~g} \mathrm{~L}^{-1}\right)$ under the $\mathrm{pH}$-control strategy. Furthermore, the butyrate/butanol ratio reached the highest level of $0.80 \mathrm{~g} \mathrm{~g}^{-1}$ with vanillin/vanillic acid co-addition, and solvent concentration reached $13.85 \mathrm{~g} \mathrm{~L}^{-1}$, a comparable level to the control $(13.69 \mathrm{~g}$ $\mathrm{L}^{-1}$ ). The effectiveness and robustness of the strategy for solvent and organic acid co-production was also verified under five typical phenolic environments. In conclusion, these results suggest that the proposed process strategy would potentially promote butanol fermentative products from renewable biomass.

Received 14th January 2019 Accepted 21st February 2019

DOI: 10.1039/c9ra00325h

rsc.li/rsc-advances mainly produced via an anaerobic fermentation process by solventogenic clostridia including Clostridium acetobutylicum and $C$. beijerinckii, but it markedly inhibits the cell growth and metabolism of producing strains at a butanol concentration in the fermentation broth beyond the tolerance threshold value of $\sim 10 \mathrm{~g} \mathrm{~L}^{-1} .{ }^{4,5}$ Moreover, butanol fermentation (i.e., acetonebutanol-ethanol or ABE fermentation) is associated with several drawbacks, such as low butanol titre and productivity, and elevated cost of raw feedstock. ${ }^{6}$ Of these, high raw material cost is the major limiting factor for the large-scale application of biobutanol as an alternative biofuel or platform chemical. ${ }^{7,8}$

Lignocellulosic biomasses are considered as abundant and renewable feedstocks for the fermentative production of butanol and other fine chemicals. ${ }^{9}$ However, the effective utilization of lignocellulosic biomass for chemicals production necessitates a pre-treatment process for disrupting the close inter-component association between cellulose, hemicellulose, and lignin. ${ }^{10}$ Although raw materials cost could be efficiently decreased by utilizing lignocellulose for butanol production, the detoxification process of lignocellulosic hydrolysate even
${ }^{a}$ School of Life Science and Food Engineering, Huaiyin Institute of Technology, Huaian 223003, China.E-mail: hzluo@hyit.edu.cn

${ }^{b}$ Department of Chemistry, Missouri University of Science and Technology, Rolla, MO 65409, USA 
might increase the total production cost. ${ }^{11}$ It is mainly attributed to the presence of inhibitory compounds in lignocellulosic hydrolysate, which deteriorate butanol fermentation performance. For instance, formic acid, acetate, furfural, 5-hydroxymethylfurfural (5-HMF), and phenolics are generated during pre-treatment of lignocellulose. ${ }^{12}$ Some of these biomassderived compounds are known to inhibit several strains including C. acetobutylicum, C. beijerinckii and C. saccharoperbutylacetonicum. ${ }^{\mathbf{1 3 - 1 5}}$ Some studies reported that the concentration of phenolics degraded from lignin in the real lignocellulosic hydrolysates was about $2-4 \mathrm{~g} \mathrm{~L}^{-1} \cdot{ }^{16,17}$ In addition, the lignin-derived phenolics are generally more toxic to microorganisms than furan derivatives, ${ }^{\mathbf{1 8 , 1 9}}$ but several solventogenic clostridia could tolerate low concentration of phenolics $\left(<0.5 \mathrm{~g} \mathrm{~L}^{-1}\right){ }^{15}$ Recently, Baral and $\mathrm{Shah}^{13}$ reviewed and evaluated the removal efficiency of phenolics in hydrolysate via multiple methods including laccase treatment, over-liming treatment, and anion exchange treatment. However, low concentration of phenolics $\left(\sim 0.1-0.5 \mathrm{~g} \mathrm{~L}^{-1}\right)$ still present in lignocellulosic hydrolysates after detoxification process, and the influences of these phenolics on the overall performance of solvents synthesis, cells growth, off-gas and organic acids synthesis have not been investigated adequately.

On the other hand, solventogenic clostridia are characterized by a biphasic metabolic pathway i.e., acidogenesis and solventogenesis. Production of butyrate and acetate are generally regarded as the main by-products in butanol fermentation because the separation of organic acids would increase the cost of the downstream process and deteriorate the whole economics of butanol production. One recent study reported that butyl butyrate, a value-added chemical and biofuel, can be successfully produced in butanol fermentation by engineered $C$. beijerinckii spooA mutant ${ }^{20}$ because this engineered strain exhibited a significant potential to accumulate high amounts of butyrate $\left(8.96 \mathrm{~g} \mathrm{~L}^{-1}\right)$ and butanol $\left(3.32 \mathrm{~g} \mathrm{~L}^{-1}\right)$ from $60 \mathrm{~g} \mathrm{~L}^{-1}$ glucose with a pH-control strategy. Through the simultaneous butanol fermentation, condensation, and extraction, $3.32 \mathrm{~g} \mathrm{~L}^{-1}$ butyl butyrate was obtained in the hexadecane layer, ${ }^{20}$ which provides a novel process strategy for the biosynthesis of valueadded chemicals via butanol fermentation. In addition, other reports related to butyl butyrate, ${ }^{21-23}$ butyl oleate, ${ }^{24}$ bio-lipids ${ }^{25}$ or other chemicals productions in butanol fermentation with esterification technology have also been documented in the past five years. ${ }^{26}$ Our previous studies have demonstrated that acetone can be synthesized from acetate in butanol fermentation by $C$. acetobutylicum ATCC 824..$^{27,28}$ Thus, solvents (acetone, butanol, and ethanol) and organic acids (butyrate and acetate) co-production in the fermentation process is a highly desirable target/objective for extending the application scope of butanol fermentation.

In this study, the effects of five typical lignin-derived phenolics on butanol fermentation performance by C. acetobutylicum ATCC 824 in both $100 \mathrm{~mL}$ anaerobic bottles and $5 \mathrm{~L}$ fermenter were investigated. Different strategies for alleviation of the "acid crash" phenomenon in butanol fermentation were also evaluated and executed in a $5 \mathrm{~L}$ anaerobic fermenter. In addition, the combined phenolics addition was performed to increase the concentration of solvents and organic acids. Finally, a novel fermentation strategy for the co-production of solvents and organic acids with lignin-derived phenolics existence was proposed, which might have a potential for the production of fine chemicals (such as butyl butyrate, butyl acetate, etc.) from cheaper lignocellulosic feedstocks.

\section{Experimental}

\subsection{Strain and media}

Clostridium acetobutylicum ATCC 824 was used as a host strain for butanol fermentation in this study. The strain was maintained and preserved as spores in cornmeal $(5 \%, \mathrm{w} / \mathrm{v})$ medium as reported in our previous study. ${ }^{28}$ Clostridial growth medium (CGM) consisting of ( $\left.\mathrm{g} \mathrm{L}^{-1}\right): \mathrm{KH}_{2} \mathrm{PO}_{4} 0.75, \mathrm{~K}_{2} \mathrm{HPO}_{4} 0.75, \mathrm{NaCl}$ 1.0, $\mathrm{MnSO}_{4} \cdot 5 \mathrm{H}_{2} \mathrm{O} 0.017, \mathrm{MgSO}_{4} \cdot 7 \mathrm{H}_{2} \mathrm{O} 0.70, \mathrm{FeSO}_{4} \cdot 7 \mathrm{H}_{2} \mathrm{O} 0.01$, L-asparagine 2.0, yeast extract 5.0, $\left(\mathrm{NH}_{4}\right)_{2} \mathrm{SO}_{4} 2.0$, and glucose 30 was used as a seed medium for the germination of strain. ${ }^{29} \mathrm{CGM}$ was also used as fermentation medium to produce solvents and organic acids. It should be noted that the initial glucose concentration in the fermentation medium was $60 \mathrm{~g} \mathrm{~L}^{-1}$.

\subsection{Selection of lignin-derived phenolics}

Five typical lignin-derived phenolics including vanillin, vanillic acid, $p$-hydroxybenzaldehyde, $p$-hydroxybenzoic acid, and ferulic acid (Sigma-Aldrich) were considered in this study. All these phenolics were added in the fermentation medium before $\mathrm{pH}$ adjustment and the dosage was adjusted according to the requirements.

\subsection{Fermentation conditions and experimental setup}

Seed cultures were carried out in $100 \mathrm{~mL}$ anaerobic bottles containing $50 \mathrm{~mL}$ seed medium. A $5 \mathrm{~mL}$ spore suspension of the strain was inoculated in the anaerobic bottles and then vacuumized by a vacuum pump for $2 \mathrm{~min}$. The seed culture was placed on a thermostat water bath at $37^{\circ} \mathrm{C}$ for $24 \mathrm{~h}$. For butanol production, a $10 \%(\mathrm{v} / \mathrm{v})$ seed culture was inoculated into $100 \mathrm{~mL}$ anaerobic bottles containing $50 \mathrm{~mL}$ fermentation medium. The bottles were vacuumed for $2 \mathrm{~min}$ to eliminate oxygen dissolved in the medium and then placed at $37{ }^{\circ} \mathrm{C}$ in a water bath for fermentation. In this case, lignin-derived phenolics were added in CGM with the dosage of $0-1.0 \mathrm{~g} \mathrm{~L}^{-1}$ and the initial $\mathrm{pH}$ of culture was adjusted to 5.0. The off-gas $\left(\mathrm{H}_{2}+\mathrm{CO}_{2}\right)$ produced by C. acetobutylicum ATCC 824 was discharged manually every 4$5 \mathrm{~h}$. The butanol fermentation was ended at $72 \mathrm{~h}$ without controlling $\mathrm{pH}$ throughout the process. The butanol fermentation was also implemented in the $5 \mathrm{~L}$ anaerobic fermentor (BLBIO-5GJ, Shanghai Bailun Bioengineering Co., Ltd., China), loaded with $3 \mathrm{~L}$ fermentation medium at an inoculum size of $10 \%(\mathrm{v} / \mathrm{v})$. Before inoculation, $\mathrm{N}_{2}(>99.99 \%)$ was sparged for 20 min to remove dissolved oxygen in CGM. During fermentation, the temperature was maintained at $37{ }^{\circ} \mathrm{C}$ and agitation speed was controlled at $100 \mathrm{rpm}$. The experimental setup of butanol fermentation in $5 \mathrm{~L}$ anaerobic fermenter is shown in Fig. 1. An optimized pH-control strategy during butanol fermentation was described as follows: $\mathrm{pH}$ was controlled at 5.0 


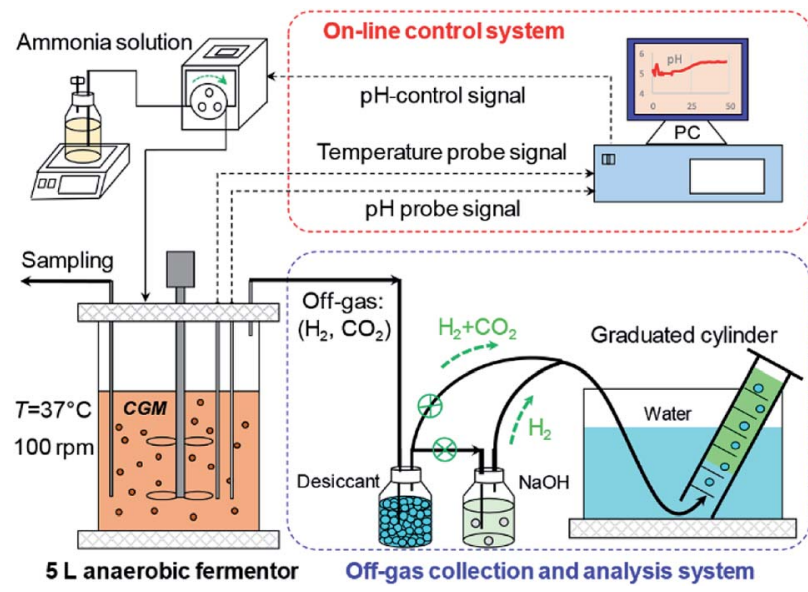

Fig. 1 Experimental setup for the co-production of solvents and organic acids in butanol fermentation by $C$. acetobutylicum.

by automatically feeding a $25 \%(\mathrm{w} / \mathrm{v})$ ammonia solution during acidogenesis $(0-15 \mathrm{~h})$, and it was not controlled when $\mathrm{pH}$ became higher than 5.0 during solventogenesis $(15-48 \mathrm{~h})$. The produced gas was measured by the off-gas collection and analysis system (Fig. 1) and fermentation was ended at $48 \mathrm{~h}$.

\subsection{Analytical methods}

The concentration of glucose and products in the fermentation broth was analysed after removing cells by centrifugation at $10000 \times g$ for $10 \mathrm{~min}$. The concentration of butanol, acetone, ethanol, acetate, and butyrate was measured by a gas chromatograph (GC3900) equipped with a flame ionization detector (FID) and FFAP column $(30 \mathrm{~m} \times 0.32 \mathrm{~mm} \times 0.5 \mu \mathrm{m})$. The oven was programmed to heat from $60{ }^{\circ} \mathrm{C}$ to $210{ }^{\circ} \mathrm{C}$ with a heating rate of $15{ }^{\circ} \mathrm{C} \mathrm{min}^{-1}$. Iso-butanol was used as the internal standard. ${ }^{30}$ The residual glucose concentration in broth was measured by a biosensors analyser (S-10, Shenzhen Siemen Technology Co., Ltd., China). The concentration of vanillin and vanillic acid in fermentation broth was determined by an Agilent HPLC system. ${ }^{31}$ Cells growth of C. acetobutylicum ATCC 824 was monitored by measuring the optical density at $600 \mathrm{~nm}$ $\left(\mathrm{OD}_{600}\right)$ using a UV-visible spectrophotometer (UV-2100, Unico Instrument Co., Ltd., Shanghai).

\subsection{Statistical analysis}

Data were statistically analysed using the statistical software package (SPSS Statics 21). The means, and standard derivations of means (mean $\pm \mathrm{SD}$ ) were calculated for three independent replicates, and SD values have been displayed as $Y$-error bars in figures.

\section{Results}

\subsection{Effects of phenolics on butanol fermentation without a pH-control strategy}

In order to investigate the effects of lignin-derived phenolics on butanol fermentation by C. acetobutylicum ATCC 824 without a pH-control strategy, five typical phenolics (vanillin, vanillic acid, $p$-hydroxybenzaldehyde, $p$-hydroxybenzoic acid, and ferulic acid) were selected in this study. The fermentations were carried out in $100 \mathrm{~mL}$ anaerobic bottles with an initial glucose concentration of $60 \mathrm{~g} \mathrm{~L}^{-1}$, and the addition dosage of each phenolic compound in CGM was $0-1.0 \mathrm{~g} \mathrm{~L}^{-1}$. The initial $\mathrm{pH}$ of fermentation medium in these cases was 5.0. As shown in Table 1, $10.29 \mathrm{~g} \mathrm{~L}^{-1}$ butanol, $3.12 \mathrm{~g} \mathrm{~L}^{-1}$ acetone, and $1.04 \mathrm{~g} \mathrm{~L}^{-1}$ ethanol was produced in $72 \mathrm{~h}$, with total acetone-butanolethanol (ABE) concentration of $14.45 \mathrm{~g} \mathrm{~L}^{-1}$ without the addition of phenolics (control). The final concentration of acetate, butyrate, and total acids was $0.78 \mathrm{~g} \mathrm{~L}^{-1}, 0.66 \mathrm{~g} \mathrm{~L}^{-1}$, and $1.44 \mathrm{~g}$ $\mathrm{L}^{-1}$, respectively. ABE yield on glucose was $0.29 \mathrm{~g} \mathrm{~g}^{-1}$ by consumption of $49.72 \mathrm{~g} \mathrm{~L}^{-1}$ glucose. Previous studies have reported that more than $0.5 \mathrm{~g} \mathrm{~L}^{-1}$ lignin-derived phenolics inhibit butanol synthesis in solventogenic clostridia. ${ }^{18,32}$ Herein, the results indicated that butanol concentration was not reduced and even enhanced from $10.29 \mathrm{~g} \mathrm{~L}^{-1}$ to $11.36 \mathrm{~g} \mathrm{~L}^{-1}$ with $10.4 \%$ increment by the addition of $0.1 \mathrm{~g} \mathrm{~L}^{-1}$ vanillin. In this case, total ABE concentration $\left(15.98 \mathrm{~g} \mathrm{~L}^{-1}\right), \mathrm{ABE}$ productivity $\left(0.22 \mathrm{~g} \mathrm{~L}^{-1}\right.$ $\mathrm{h}^{-1}$ ), ABE yield on glucose $\left(0.34 \mathrm{~g} \mathrm{~g}^{-1}\right)$, and final $\mathrm{OD}_{600}(2.59)$ were enhanced in comparison with the control, which coincided with the butyrate fermentation results by $C$. tyrobutyricum ATCC $25755 .{ }^{31}$ When elevating the vanillin addition amount from $0.2 \mathrm{~g} \mathrm{~L}^{-1}$ to $1.0 \mathrm{~g} \mathrm{~L}^{-1}$, butanol fermentation performance was inhibited gradually (Table 1 ). However, the final $\mathrm{OD}_{600}$ was still higher than that of control when the addition dosage of vanillin was in the range of $0.1-0.8 \mathrm{~g} \mathrm{~L}^{-1}$, which indicated that lower vanillin concentration did not inhibit the cells growth of C. acetobutylicum ATCC 824 .

When adding vanillic acid in CGM, butanol fermentation performance was remarkably deteriorated even though the initial adding concentration was as low as $0.1 \mathrm{~g} \mathrm{~L}^{-1}\left(4.23 \mathrm{~g} \mathrm{~L}^{-1}\right.$ butanol vs. $10.29 \mathrm{~g} \mathrm{~L} \mathrm{~L}^{-1}$ butanol, Table 1). The glucose consumption of only $21.19 \mathrm{~g} \mathrm{~L}^{-1}$ in $72 \mathrm{~h}$ demonstrated the strong inhibitory effect of vanillic acid on cells metabolism. Here, it should be noted that the total acids concentration reached a higher level of 1.67-4.15 $\mathrm{g} \mathrm{L}^{-1}$ with 0.1-0.4 $\mathrm{g} \mathrm{L}^{-1}$ vanillic acid addition and the final $\mathrm{pH}$ reached a low level of 3.80. The results revealed that butanol fermentation was ended in acidogenesis mainly attributed to the "acid crash" effect. ${ }^{33,34}$ As shown in Table 1, the cells growth, solvents synthesis and glucose consumption amount of $C$. acetobutylicum were inhibited largely when adding $0.1-1.0 \mathrm{~g} \mathrm{~L}^{-1}$ of $p$-hydroxybenzaldehyde, $p$-hydroxybenzoic acid, and ferulic acid in CGM.

The results obtained above indicated that adding sole ligninderived phenolic compound influenced butanol fermentation performance. However, the effects of two phenolics addition on butanol fermentation in CGM were not investigated so far. Based on the positive effect of vanillin addition on butanol synthesis (Table 1), we speculated that simultaneous addition vanillin and other lignin-derived phenolic compounds might have synergistic effects on butanol fermentation. Therefore, four combinations such as vanillin \& vanillic acid, vanillin \& $p$ hydroxybenzaldehyde, vanillin \& $p$-hydroxybenzoic acid, and vanillin \& ferulic acid, were designed to evaluate their inhibitory effects on butanol fermentation in $100 \mathrm{~mL}$ anaerobic bottles. Each phenolic compound concentration was $0.1 \mathrm{~g} \mathrm{~L}^{-1}$ with 
Table 1 Butanol fermentation performance in $100 \mathrm{~mL}$ anaerobic bottles containing exogenously added lignin-derived phenolics ${ }^{a b}$

\begin{tabular}{|c|c|c|c|c|c|c|c|c|c|c|c|c|}
\hline \multirow[b]{2}{*}{ Operation mode ${ }^{c}$} & \multicolumn{4}{|c|}{$\begin{array}{l}\text { Solvents } \\
\text { concentration }\left(\mathrm{g} \mathrm{L}^{-1}\right)\end{array}$} & \multirow[b]{2}{*}{$P_{\mathrm{ABE}}\left(\mathrm{g} \mathrm{L}^{-1} \mathrm{~h}^{-1}\right)$} & \multicolumn{3}{|c|}{$\begin{array}{l}\text { Organic acids } \\
\text { conc. }\left(\mathrm{g} \mathrm{L}^{-1}\right)\end{array}$} & \multirow[b]{2}{*}{$C_{\mathrm{Glc}}\left(\mathrm{g} \mathrm{L}^{-1}\right)$} & \multirow[b]{2}{*}{$Y_{\mathrm{ABE}}\left(\mathrm{g} \mathrm{g}^{-1}\right)$} & \multirow[b]{2}{*}{ Final $\mathrm{OD}_{600}$} & \multirow[b]{2}{*}{ Final $\mathrm{pH}^{h}$} \\
\hline & $\mathrm{BtOH}$ & ACE & EtOH & $\mathrm{ABE}$ & & AA & $\mathrm{BA}$ & Acids & & & & \\
\hline Control & 10.29 & 3.12 & 1.04 & 14.45 & 0.20 & 0.78 & 0.66 & 1.44 & 49.72 & 0.29 & 2.56 & 4.43 \\
\hline Vanillin 0.1 & 11.36 & 3.44 & 1.18 & 15.98 & 0.22 & 0.68 & 0.70 & 1.38 & 46.96 & 0.34 & 2.59 & 4.55 \\
\hline Vanillin 0.2 & 9.90 & 3.15 & 1.07 & 14.12 & 0.20 & 0.80 & 0.75 & 1.55 & 42.56 & 0.33 & 2.81 & 4.46 \\
\hline Vanillin 1.0 & 4.43 & 0.84 & 0.29 & 5.56 & 0.08 & 0.44 & 0.26 & 0.70 & 22.46 & 0.25 & 1.24 & 4.33 \\
\hline Vanillic acid 0.1 & 4.23 & 2.08 & 0.44 & 6.98 & 0.10 & 0.84 & 0.83 & 1.67 & 21.19 & 0.33 & 1.73 & 3.82 \\
\hline Vanillic acid 0.2 & 0.79 & 0.57 & 0.07 & 1.43 & 0.02 & 0.82 & 1.20 & 2.02 & 15.57 & 0.09 & 1.43 & 3.81 \\
\hline Vanillic acid 0.4 & 0.71 & 0.60 & 0.20 & 1.51 & 0.02 & 1.59 & 2.56 & 4.15 & 14.10 & 0.11 & 1.24 & 3.80 \\
\hline Vanillic acid 0.8 & 0.21 & 0.47 & 0.11 & 0.79 & 0.01 & 0.56 & 0.40 & 0.96 & 13.47 & 0.06 & 0.65 & 4.22 \\
\hline Vanillic acid 1.0 & 0.28 & 0.29 & 0.07 & 0.64 & 0.01 & 0.40 & 0.60 & 1.00 & 7.50 & 0.09 & 0.47 & 4.21 \\
\hline$p$-Hydroxybenzaldehyde 1.0 & 0.78 & 0.17 & 0.07 & 1.02 & 0.01 & 0.90 & 0.68 & 1.58 & 10.54 & 0.10 & 1.80 & 3.90 \\
\hline$p$-Hydroxybenzoic acid 0.1 & 5.97 & 1.59 & 0.40 & 7.96 & 0.11 & 0.93 & 0.60 & 1.53 & 32.58 & 0.24 & 1.21 & 4.19 \\
\hline p-Hydroxybenzoic acid 0.2 & 1.66 & 0.73 & 0.21 & 2.60 & 0.04 & 1.20 & 1.23 & 2.43 & 16.69 & 0.16 & 1.19 & 3.84 \\
\hline$p$-Hydroxybenzoic acid 0.4 & 0.64 & 0.44 & 0.15 & 1.23 & 0.02 & 0.55 & 0.81 & 1.36 & 15.05 & 0.08 & 0.56 & 3.78 \\
\hline p-Hydroxybenzoic acid 0.8 & 0.78 & 0.49 & 0.25 & 1.52 & 0.02 & 0.39 & 0.49 & 0.88 & 9.72 & 0.16 & 0.33 & 4.09 \\
\hline p-Hydroxybenzoic acid 1.0 & 0.61 & 0.32 & 0.10 & 1.03 & 0.01 & 0.59 & 0.52 & 1.11 & 12.18 & 0.08 & 0.19 & 4.33 \\
\hline Ferulic acid 0.1 & 4.48 & 1.68 & 0.51 & 6.67 & 0.09 & 1.56 & 1.25 & 2.81 & 23.34 & 0.29 & 1.82 & 4.25 \\
\hline Ferulic acid 0.2 & 2.12 & 0.77 & 0.23 & 3.12 & 0.04 & 1.07 & 0.80 & 1.87 & 18.51 & 0.17 & 1.95 & 3.77 \\
\hline Ferulic acid 0.4 & 1.49 & 0.60 & 0.23 & 2.32 & 0.03 & 0.97 & 0.60 & 1.57 & 17.67 & 0.13 & 2.08 & 3.83 \\
\hline Ferulic acid 0.8 & 0.24 & 0.47 & 0.16 & 0.87 & 0.01 & 0.70 & 0.24 & 0.94 & 6.33 & 0.14 & 0.43 & 4.20 \\
\hline Ferulic acid 1.0 & 0.17 & 0.31 & 0.08 & 0.56 & 0.01 & 0.40 & 0.15 & 0.55 & 6.12 & 0.09 & 0.49 & 4.51 \\
\hline Combined mode $\# 1^{d}$ & 2.80 & 0.96 & 0.22 & 3.94 & 0.05 & 0.50 & 0.54 & 1.04 & 15.40 & 0.26 & 1.79 & 3.83 \\
\hline Combined mode $\# 2^{e}$ & 2.08 & 0.72 & 0.17 & 2.97 & 0.04 & 0.56 & 0.47 & 1.03 & 17.10 & 0.17 & 1.99 & 3.77 \\
\hline
\end{tabular}

${ }^{a} \mathrm{BtOH}$, butanol; ACE, acetone; EtOH, ethanol; ABE, total solvents; AA, acetate; BA, butyrate; acids, total organic acids (i.e., acetate and butyrate); $P_{\mathrm{ABE}}, \mathrm{ABE}$ productivity; $C_{\mathrm{Glc}}$, glucose consumption; $Y_{\mathrm{ABE}}$, ABE yield on glucose consumption. ${ }^{b}$ Each batch culture was performed three times, and the average was represented in Table 1. It should be noted that the parameters in Table 1 were calculated after $72 \mathrm{~h}$ of fermentation without a pH-control strategy. ${ }^{c}$ The values followed by lignin-derived phenolics were the corresponding phenolic adding dosage $\left(\mathrm{g} \mathrm{L}^{-1}\right)$ in $\mathrm{CGM}^{-}$ ${ }^{d}$ Adding vanillin $\left(0.1 \mathrm{~g} \mathrm{~L}^{-1}\right)$ and vanillic acid $\left(0.1 \mathrm{~g} \mathrm{~L}^{-1}\right)$ simultaneously in CGM. ${ }^{e}$ Adding vanillin $\left(0.1 \mathrm{~g} \mathrm{~L}^{-1}\right)$ and $p$-hydroxybenzaldehyde $\left(0.1 \mathrm{~g} \mathrm{~L}^{-1}\right)$ simultaneously in CGM. ${ }^{f}$ Adding vanillin $\left(0.1 \mathrm{~g} \mathrm{~L}^{-1}\right)$ and $p$-hydroxybenzoic acid $\left(0.1 \mathrm{~g} \mathrm{~L}^{-1}\right)$ simultaneously in CGM. ${ }^{g}$ Adding vanillin $\left(0.1 \mathrm{~g} \mathrm{~L}^{-1}\right)$ and ferulic acid $\left(0.1 \mathrm{~g} \mathrm{~L}^{-1}\right)$ simultaneously in CGM. ${ }^{h}$ The initial $\mathrm{pH}$ of CGM was 5.0 in the cases of lignin-derived phenolics addition.

a total amount of $0.2 \mathrm{~g} \mathrm{~L}^{-1}$ phenolics. Results in Table 1 represents that the butanol concentration and final $\mathrm{OD}_{600}$ reached $11.10 \mathrm{~g} \mathrm{~L}^{-1}$ and 2.48 , respectively, with a glucose consumption of $51.10 \mathrm{~g} \mathrm{~L}^{-1}$ in case of simultaneous addition of vanillin \& ferulic acid, which was almost the same as purely adding $0.1 \mathrm{~g} \mathrm{~L}^{-1}$ vanillin. However, butanol fermentation performance of the other three combinations was inhibited dramatically and recorded in the range of $1.64-2.80 \mathrm{~g} \mathrm{~L}^{-1}$, which were much lower than that the addition of pure phenolic compound $\left(0.1 \mathrm{~g} \mathrm{~L}^{-1}\right)$. Thus, the synergistic inhibitory effect of lignin-derived phenolics on butanol fermentation exists in $100 \mathrm{~mL}$ anaerobic bottles without a pH-control strategy. Although the chemical structure of vanillic acid and vanillin are similar, the co-existence features of vanillic acid and vanillin in broth during the butanol fermentation process remain to be elucidated. Furthermore, lower final $\mathrm{pH}$ value (3.8) and the "acid crash" phenomenon in these cases might be deciphered by a pH-control strategy in the anaerobic fermenter.

\subsection{Alleviation of "acid crash" of butanol fermentation with a pH-control strategy}

In the above section, we have investigated the effects of phenolics on butanol fermentation performance in $100 \mathrm{~mL}$ anaerobic bottles. However, in these cases, the culture pH was not controlled and the pressure in headspace was higher than that of atmosphere during the fermentation process. Therefore, the environment for butanol fermentation by C. acetobutylicum will profoundly change, when scaling-up from $100 \mathrm{~mL}$ anaerobic bottles to $5 \mathrm{~L}$ anaerobic fermenter. Here, two typical fermentation batches (\#1 and \#2) were implemented with different $\mathrm{pH}$ strategies. In fermentation batch $\# 1$, the $\mathrm{pH}$ of culture was not controlled, and $\mathrm{pH}$-changing patterns is portrayed in Fig. 2a. Clearly, the culture $\mathrm{pH}$ was gradually reduced from $4.6(0 \mathrm{~h})$ to $3.7(48 \mathrm{~h})$, and glucose consumption and final $\mathrm{OD}_{600}$ were only $17.22 \mathrm{~g} \mathrm{~L}^{-1}$ and 2.63 , respectively. In this case, a lower level of $1.16 \mathrm{~g} \mathrm{~L}^{-1}$ butanol and $1.79 \mathrm{~g} \mathrm{~L}^{-1}$ total ABE was 

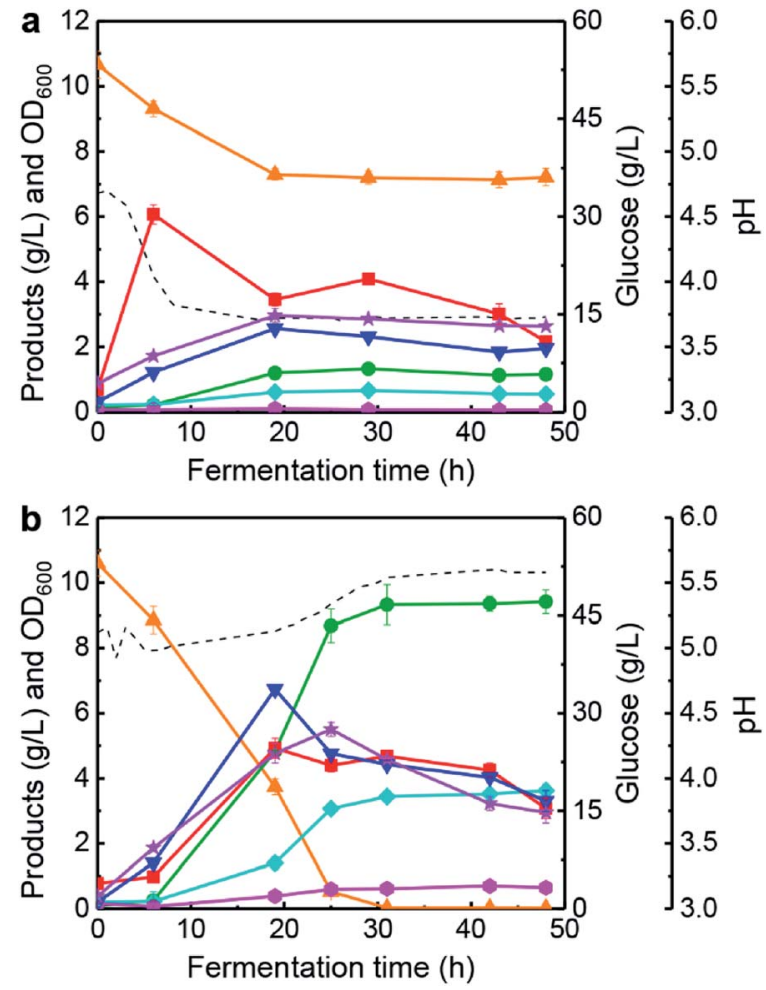

Fig. 2 The time courses of butanol fermentation under different strategies. (a) Without a $\mathrm{pH}$-control strategy, batch \#1; (b) with a pHcontrol strategy, batch \#2. - butanol; : acetone; ethanol; acetate; $\mathbf{\nabla}$ : butyrate; $\star: \mathrm{OD}_{600} ; \boldsymbol{\Delta}$ : glucose; broken line: $\mathrm{pH}$.

produced by $C$. acetobutylicum. At the completion of fermentation, final organic acids concentrations reached higher levels: $1.95 \mathrm{~g} \mathrm{~L}^{-1}$ butyrate, $2.16 \mathrm{~g} \mathrm{~L}^{-1}$ acetate, and $4.11 \mathrm{~g} \mathrm{~L}^{-1}$ total acids. Various studies have reported that excessive accumulation of undissociated butyrate ${ }^{33}$ and acetate ${ }^{35}$ are detrimental to solventogenic clostridia (such as C. acetobutylicum and C. beijerinckii) for glucose uptake, cells growth and solvents synthesis. The findings were consistent with the above reports, and butanol fermentation was ended by "acid crash" with a low $\mathrm{pH}$ environment (Fig. 2a). Therefore, further fermentation strategy with a pH-control should be developed to alleviate the "acid crash" phenomenon.

A biphasic metabolic pathway including acidogenesis and solventogenesis characterizes butanol production by $C$. acetobutylicum. The main metabolites of acetate and butyrate are produced during acidogenesis. However, the accumulation of organic acids causes a drop in the broth $\mathrm{pH}$ and thus triggering the solventogenesis. Subsequently, the organic acids are reassimilated for acetone, ethanol and butanol productions. Reports have demonstrated that organic acids production and cells growth by clostridia are improved at a higher $\mathrm{pH}$ environment. ${ }^{\mathbf{4} 36}$ Also, some studies have revealed that $\mathrm{pH}$-control strategy is an efficient method for enhancing the butanol fermentation performance. ${ }^{37,38}$ Based on the results of preliminary experiments, we found that solvents synthesis in butanol fermentation was not inhibited at the $\mathrm{pH}$ higher than 5.0. Thus, an optimized $\mathrm{pH}$-control strategy was proposed: where $\mathrm{pH}$ was automatically controlled at 5.0 with ammonia solution feeding during acidogenesis ( $0-15 \mathrm{~h})$ via the on-line control system (Fig. 1), and then not controlled when $\mathrm{pH}$ was higher than 5.0 during solventogenesis (15-48 h). As shown in Fig. 2b (batch $\# 2$ ), the culture $\mathrm{pH}$ was maintained at $>5.0$ and glucose was entirely consumed at $31 \mathrm{~h}$ by the cells. The highest $\mathrm{OD}_{600}$ in batch \#2 was 5.51 at $25 \mathrm{~h}$, which was about 2-fold in comparison with that of batch \#1 without a pH-control strategy (Fig. 2a). At the fermentation end ( $48 \mathrm{~h}), 9.42 \mathrm{~g} \mathrm{~L}^{-1}$ butanol with a total $13.69 \mathrm{~g} \mathrm{~L}^{-1} \mathrm{ABE}$ were produced. Although the final acids concentrations $\left(3.08 \mathrm{~g} \mathrm{~L}^{-1}\right.$ acetate, $3.30 \mathrm{~g} \mathrm{~L}^{-1}$ butyrate, and $6.38 \mathrm{~g} \mathrm{~L}^{-1}$ total acids) with a pH-control strategy reached high levels, the butanol titre was still significantly improved from $1.16 \mathrm{~g} \mathrm{~L}^{-1}$ to $9.42 \mathrm{~g} \mathrm{~L}^{-1}$ with $712 \%$ increment. The results indicated that the "acid crash" phenomenon in batch \#1 was successfully alleviated. Subsequently, the proposed $\mathrm{pH}$-control strategy was used for investigating the kinetics of butanol fermentation in a $5 \mathrm{~L}$ anaerobic fermenter under the environment of lignin-derived phenolics existence.

\subsection{Solvents and organic acids co-production in butanol fermentation with phenolics existence}

The changing patterns of butanol fermentation without ligninderived phenolics addition have been investigated in a $5 \mathrm{~L}$ anaerobic fermenter with the proposed $\mathrm{pH}$-control strategy (batch \#2). Generally, vanillin and vanillic acid are typical phenolics derived from lignin degradation during pretreatment of lignocellulosic biomasses. ${ }^{10,39}$ Based on the results in Table $1,0.2 \mathrm{~g} \mathrm{~L}^{-1}$ vanillin was added in the butanol fermentation medium to analyse the changing feature of bioprocess kinetic parameters (batch \#3). Fig. 3a portrays that butanol fermentation performance was not inhibited largely, and final solvents concentration reached $12.57 \mathrm{~g} \mathrm{~L}^{-1}$ in $48 \mathrm{~h}$ ( $v s$. $13.69 \mathrm{~g} \mathrm{~L}^{-1}$, batch \#2). In this case, final butanol concentration and the highest $\mathrm{OD}_{600}$ were $8.58 \mathrm{~g} \mathrm{~L}^{-1}(48 \mathrm{~h})$ and $7.55(26 \mathrm{~h})$, respectively. Results indicated the improvement of cells growth could be achieved by the addition of $0.2 \mathrm{~g} \mathrm{~L}^{-1}$ vanillin in the fermentation medium. Moreover, a final concentration of butyrate and acetate was $5.75 \mathrm{~g} \mathrm{~L}^{-1}$ and $5.04 \mathrm{~g} \mathrm{~L}^{-1}$, respectively. The total acids concentration of $10.79 \mathrm{~g} \mathrm{~L}^{-1}$ was much higher than that of batch \#2 $\left(6.38 \mathrm{~g} \mathrm{~L}^{-1}\right)$. With an addition of $0.2 \mathrm{~g} \mathrm{~L}^{-1}$ vanillic acid (batch \#4), butanol fermentation performance was very different from the case of vanillic acid addition in $100 \mathrm{~mL}$ anaerobic bottles (Table 1 and Fig. 3b). These differential fermentation results were mainly attributed to the multifunctionalities of the proposed $\mathrm{pH}$-control strategy in a $5 \mathrm{~L}$ fermenter. In batch \#4, the highest concentration of butanol $\left(8.42 \mathrm{~g} \mathrm{~L}^{-1}\right)$ and solvents $\left(11.77 \mathrm{~g} \mathrm{~L}^{-1}\right)$ was obtained at $33 \mathrm{~h}$, which was reduced by $10.6 \%$ and $14.0 \%$, respectively, in comparison with those of batch \#2. The highest value of $\mathrm{OD}_{600}$ (6.96) achieved at $21 \mathrm{~h}$ and glucose was consumed completely at $27 \mathrm{~h}$. At $33 \mathrm{~h}, 4.76 \mathrm{~g} \mathrm{~L}^{-1}$ butyrate and $9.21 \mathrm{~g} \mathrm{~L}^{-1}$ total acids were produced by C. acetobutylicum ATCC 824 (Fig. 3b). Based on the results obtained in batches \#3-\#4, the following conclusions could be listed: (1) C. acetobutylicum could tolerate lower concentration $\left(0-0.2 \mathrm{~g} \mathrm{~L}^{-1}\right)$ of vanillin or vanillic acid in fermenter under the $\mathrm{pH}$-control strategy. Also, lower vanillin or 

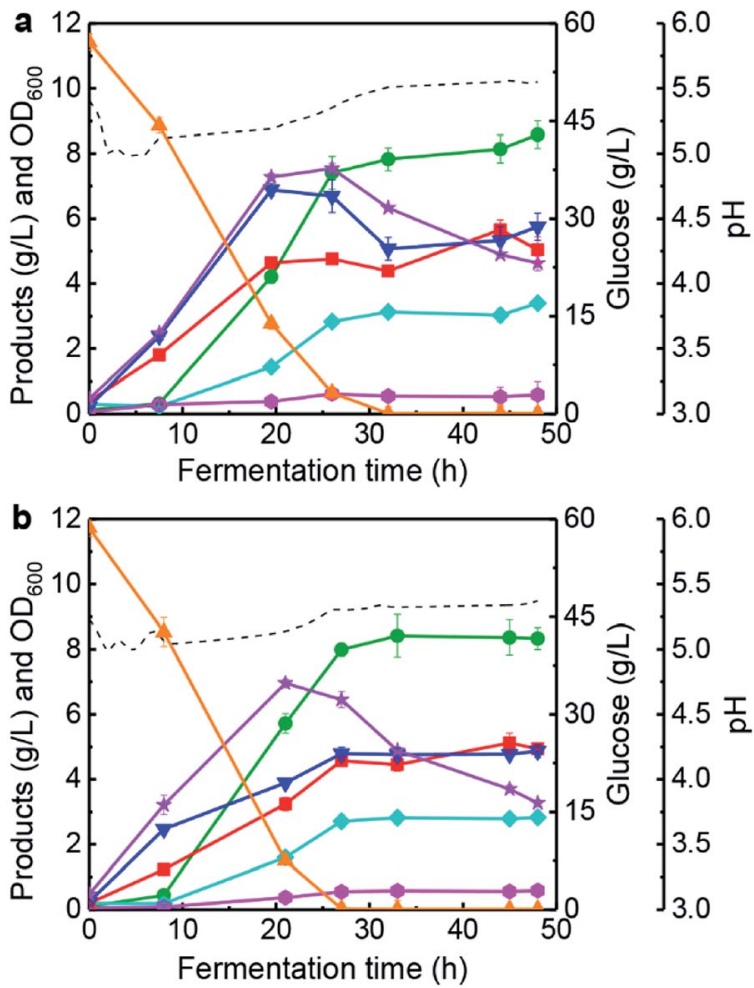

Fig. 3 The time courses of butanol fermentation with different ligninderived phenolics addition under the $\mathrm{pH}$-control strategy. (a) $0.2 \mathrm{~g} \mathrm{~L}^{-1}$ vanillin was added in the fermentation medium, batch \#3; (b) $0.2 \mathrm{~g} \mathrm{~L}^{-1}$ vanillic acid was added in the fermentation medium, batch \#4. butanol; $\star$ : acetone; $\bullet$ ethanol; $\mathbf{\square}$ acetate; $\mathbf{\nabla}$ : butyrate; $\star$ : $\mathrm{OD}_{600} ; \mathbf{\Delta}$ glucose; broken line: $\mathrm{pH}$.

vanillic acid concentration could improve the cells growth of $C$. acetobutylicum. Since those phenolic compounds are an environmental stress factors for solventogenic clostridia, ${ }^{15,40}$ and we speculated that the cells need to synthesize more energy substance such as ATP response to the phenolic stress. ${ }^{41}$ In the metabolism of C. acetobutylicum ATCC 824, ATP is mainly produced in the synthesis pathway of glycolysis, acetate, and butyrate during solventogenesis.,4,42 Therefore, higher acetate and butyrate concentrations (Fig. 3) could be reflected more ATP supply under the condition of vanillin or vanillic acid addition. (2) Implementing a pH-control strategy could accumulate solvents and organic acids simultaneously with an initial glucose concentration of $60 \mathrm{~g} \mathrm{~L}^{-1}$ in the presence of phenolic compounds (such as vanillin or vanillic acid).

As described above (Table 1), the synergistic effect of vanillin \& vanillic acid on butanol fermentation exists in anaerobic bottles. Meanwhile, the production of solvents and organic acids was enhanced to higher levels with vanillin (batch \#3) or vanillic acid (batch \#4) addition in the anaerobic fermenter. Consequently, we added $0.1 \mathrm{~g} \mathrm{~L}^{-1}$ vanillin and $0.1 \mathrm{~g} \mathrm{~L}^{-1}$ vanillic acid in CGM to investigate the process features of butanol fermentation (batch \#5). Results in Fig. 4 illustrate that $\mathrm{OD}_{600}$, acetate and butyrate concentrations were improved rapidly during $0-22 \mathrm{~h}$ (i.e., acidogenesis), while the rate of solvents synthesis was not high. After that (i.e., solventogenesis), butanol and acetone titres were improved from $4.89 \mathrm{~g} \mathrm{~L}^{-1}$ to $9.07 \mathrm{~g} \mathrm{~L}^{-1}$,

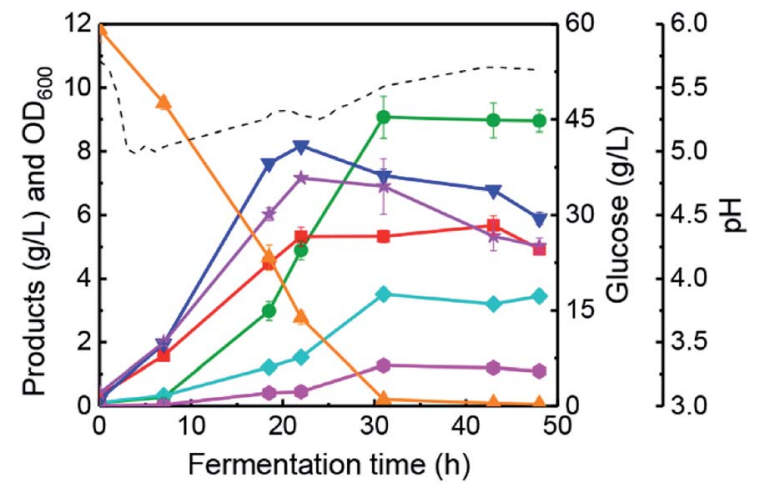

Fig. 4 The time courses of butanol fermentation with vanillin $(0.1 \mathrm{~g}$ $\left.\mathrm{L}^{-1}\right)$ and vanillic acid $\left(0.1 \mathrm{~g} \mathrm{~L}^{-1}\right)$ addition under the $\mathrm{pH}$-control strategy. $\bullet$ : butanol; : acetone; ethanol; $\mathbf{E}$ : acetate; $\mathbf{\nabla}$ : butyrate; $\star$ : $\mathrm{OD}_{600} ; \boldsymbol{\Delta}$ glucose; broken line: $\mathrm{pH}$.

and $1.53 \mathrm{~g} \mathrm{~L}^{-1}$ to $3.51 \mathrm{~g} \mathrm{~L}^{-1}$, respectively, during $22-31 \mathrm{~h}$ (Fig. 4) together with a high off-gas production rate $\left(\sim 1.0 \mathrm{~h}^{-1}\right)$. Meanwhile, $60 \mathrm{~g} \mathrm{~L}^{-1}$ initial glucose was completely assimilated within $31 \mathrm{~h}$ of fermentation. In this batch, $7.24 \mathrm{~g} \mathrm{~L}^{-1}$ butyrate was produced at $31 \mathrm{~h}$ and total acids concentration reached a high level of $12.57 \mathrm{~g} \mathrm{~L}^{-1}$. The results revealed that addition of vanillin and vanillic acid could further promote the biosynthesis of organic acids. On the other hand, butanol $\left(9.07 \mathrm{~g} \mathrm{~L}^{-1}\right.$ vs. $9.42 \mathrm{~g}$ $\left.\mathrm{L}^{-1}\right)$ and total solvents $\left(13.85 \mathrm{~g} \mathrm{~L}^{-1}\right.$ vs. $\left.13.69 \mathrm{~g} \mathrm{~L}^{-1}\right)$ were negligibly inhibited compared with batch \#2 without the addition of phenolics. To the best of our knowledge, the fermentation strategy of fermentative inhibitors addition is the first report focusing on solvents and organic acids co-production in butanol fermentation by C. acetobutylicum.

\section{Discussion}

Generally, several drawbacks hinder the large-scale application of fermentative butanol by solventogenic clostridia as an alternative biofuel. First of all, the cost of raw materials in the butanol production process is very high and the main feedstock is edible corn. ${ }^{5}$ Secondly, low tolerance of the producing strains against main-product (butanol) inhibits the synthesis efficiency of butanol when its concentration in broth is higher than $10 \mathrm{~g}$ $\mathrm{L}^{-1}{ }^{4}$ Many methods have been envisaged to overcome the above-mentioned key problems, such as applying lignocellulosic biomass (corn stover, wheat straw, etc.) as fermentative substrate for butanol production, ${ }^{43,44}$ on/off-line synthesizing other value-added chemicals (butyl butyrate, butyl oleate, biolipids, etc.) from butanol or organic acids, ${ }^{20,24}$ etc. Nevertheless, the use of lignocellulosic biomass as feedstock for butanol production necessitates a pre-treatment process, and various fermentative inhibitory compounds including lignin-derived phenolics are also generated during the process. Previous studies have focused on removing the derived phenolics in lignocellulosic hydrolysate by various technologies to alleviate the inhibitory effects on chemicals production, ${ }^{13,40,45}$ but, to the best of our knowledge, utilization of lignocellulosic hydrolysate with a low concentration of phenolics for chemicals production has not been reported. On the other hand, conversion of 
butanol or organic acids to other value-added chemicals needs exogenous addition of butyrate, ${ }^{20-22}$ butanol ${ }^{46}$ or oleic acid ${ }^{24,47}$ as one of the substrates, which substantially increases the cost of the overall production process.

In this study, the solvents (acetone, butanol, and ethanol) and organic acids (butyrate and acetate) were co-produced in butanol fermentation by a wide-type strain of $C$. acetobutylicum ATCC 824 with lignin-derived phenolics addition from glucose. A final phenolics concentration range of $0.03-0.07 \mathrm{~g} \mathrm{~L}^{-1}$ in the broth (batches \#2-\#4) indicated that $C$. acetobutylicum could metabolize phenolics for weakening their inhibitory effects (Fig. 5a). When vanillin and vanillic acid were simultaneously added in CGM, the highest butyrate/butanol ratio of $0.80 \mathrm{~g} \mathrm{~g}^{-1}$ achieved at $31 \mathrm{~h}$ with a butyrate concentration of $7.24 \mathrm{~g} \mathrm{~L}^{-1}$ (Fig. 5a). In this case, the butyrate/butanol ratio was found to be much higher than that of batch \#2 $\left(0.35 \mathrm{~g} \mathrm{~g}^{-1}\right)$ without phenolics addition. Furthermore, acids yield $\left(0.22 \mathrm{~g} \mathrm{~g}^{-1}\right)$ and solvents yield $\left(0.24 \mathrm{~g} \mathrm{~g}^{-1}\right)$ on glucose of batch $\# 5$ were at the highest level (Fig. 5b). A previous study on butanol fermentation by $C$. beijerinckii NCIMB 8052 reported that the final concentration of butyrate and acetate reached the higher levels of $1.5 \mathrm{~g}$ $\mathrm{L}^{-1}$ and $3.4 \mathrm{~g} \mathrm{~L}^{-1}$ (vs. $0.2 \mathrm{~g} \mathrm{~L}^{-1}$ and $0.7 \mathrm{~g} \mathrm{~L}^{-1}$ of control, respectively) by the addition of $1.0 \mathrm{~g} \mathrm{~L}^{-1}$ vanillic acid. ${ }^{45}$
However, the butanol fermentation, in this case, did not enter to solventogenesis from acidogenesis, and therefore, elevated titre of solvents was not achieved.

As pointed out above, if the main target/objective of $\mathrm{ABE}$ fermentation is to obtain high butanol or solvents titre, addition of phenolics with a pH-control strategy was not a suitable choice. It might be attributed to the synthesis of organic acids (butyrate and acetate) as the main by-products in butanol fermentation. In this circumstance, the metabolic flux towards butanol or solvents synthesis from glucose would be distributed for acids formation and the product (butanol or solvents) yield on glucose might be reduced, which could be reflected by Fig. 5b. However, butanol tolerance of solventogenic clostridia is low, and the downstream processing cost is very high when butanol concentration in the fermentation broth is lower than $20 \mathrm{~g} \mathrm{~L}^{-1}$. To prevent butanol inhibition and high downstream costs, production of other value-added chemicals from solvents (butanol, acetone or ethanol) and organic acids (butyrate or acetate) is thus a valued research objective.

In conventional butanol fermentation, organic acids (butyrate and acetate) are re-assimilated for solvents synthesis during solventogenesis and the final concentration of acids is $0.5-1.5 \mathrm{~g} \mathrm{~L}^{-1} .^{27,30}$ From the perspective of economics, the total
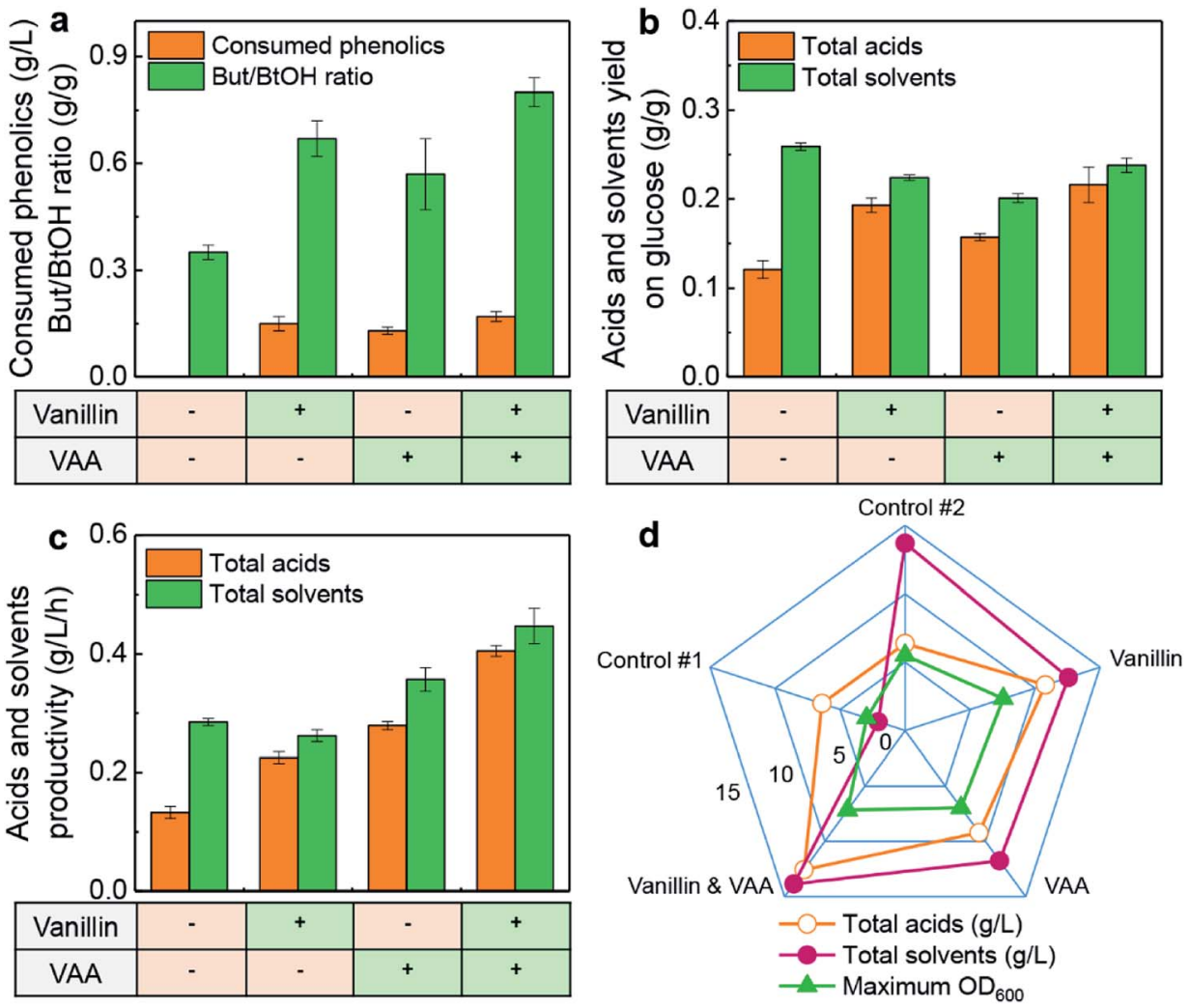

Fig. 5 Comparison of fermentation parameters with different strategies. (a) But/BtOH ratio refers to butyrate/butanol ratio ( $\mathrm{g} \mathrm{g}{ }^{-1}$ ); (b) acids and solvents yield on glucose, total acids refer to acetate and butyrate, and total solvents refer to acetone, butanol and ethanol; (c) acids and solvents productivity; (a) - (c) the symbol " -" refers to no compounds added, "+" refers to corresponding lignin-derived phenolics added, and VAA refers to vanillic acid; (d) control \#1, butanol fermentation without $\mathrm{pH}$-control, batch \#1; control \#2, butanol fermentation with $\mathrm{pH}$-control, batch \#2; vanillin, butanol fermentation with $0.2 \mathrm{~g} \mathrm{~L}^{-1}$ vanillin addition under $\mathrm{pH}$-control, batch \#3; VAA, butanol fermentation with $0.2 \mathrm{~g} \mathrm{~L}{ }^{-1}$ vanillic acid addition under $\mathrm{pH}$-control, batch \#4; vanillin \& VAA, butanol fermentation with $0.1 \mathrm{~g} \mathrm{~L}^{-1}$ vanillin and $0.1 \mathrm{~g} \mathrm{~L}^{-1}$ vanillic acid addition under pHcontrol, batch \#5; (a) - (d) the presented data in figures were based on the highest butanol concentration of each batch (batch \#1, $48 \mathrm{~h}$; batch \#2, $48 \mathrm{~h}$; batch \#3, $48 \mathrm{~h}$; batch \#4, $33 \mathrm{~h}$; batch \#5, 31 h). 
production cost of butanol will be increased due to the high cost in the separation and purification module. However, highlyefficient synthesis of butyrate and butanol is indispensable, if the main target is to obtain butyl butyrate (a biofuel is compatible with Jet A-1 aviation kerosene) in butanol fermentation by $C$. acetobutylicum without the addition of exogenous expensive butyrate. ${ }^{\mathbf{2 0 2 3}}$ Thus, the higher ratio of butyrate/ butanol ( 0.6-0.8 $\mathrm{g} \mathrm{g}^{-1}$ ) in batches \#2-\#4 would be useful for the production of butyl butyrate, and the results could also increase the products diversity in traditional butanol (ABE) fermentation. In addition, as shown in Fig. $5 c$ and $d$, the production, and productivity of acids and solvents were also improved largely compared with those of batch \#2. In the future, the potential of butyl butyrate production with lipasecatalysed esterification under the proposed strategy from real lignocellulosic hydrolysates will be explored. Furthermore, the strategy for boosting the overall fermentation performance by reducing the titre of butanol in broth with esterification and extraction processes will also be investigated.

Here, it is worth noting that real lignocellulosic hydrolysate contains more than two lignin-derived phenolics of vanillin and vanillic acid. To test the effectiveness of the proposed fermentation strategy for the co-production of solvents and organic acids, the five typical phenolics were added in CGM with a total dosage of $0.2 \mathrm{~g} \mathrm{~L}^{-1}$ (i.e., $0.04 \mathrm{~g} \mathrm{~L}^{-1}$ of each phenolic compound, batch \#6). As shown in Fig. 6, final organic acids concentration reached $7.47 \mathrm{~g} \mathrm{~L}^{-1}\left(3.79 \mathrm{~g} \mathrm{~L}^{-1}\right.$ acetate and $3.68 \mathrm{~g} \mathrm{~L}^{-1}$ butyrate $)$ at $48 \mathrm{~h}$. Interestingly, butanol concentration reached a higher level of $11.52 \mathrm{~g} \mathrm{~L}^{-1}$ (vs. $9.42 \mathrm{~g} \mathrm{~L}^{-1}$ control) with a final butyrate/ butanol ratio of $0.32 \mathrm{~g} \mathrm{~g}^{-1}$. The overall productivity of butanol was $0.24 \mathrm{~g} \mathrm{~L}^{-1} \mathrm{~h}^{-1}$ (Fig. 6), which was reduced by $19 \%$ in comparison with that of batch \#5 (Fig. 5), and glucose was consumed out at fermentation end ( $v$ s. $31 \mathrm{~h}$ of batch \#5). Although organic acids concentration in batch \#6 was lower than the case of vanillin and vanillic acid additions (batch \#5), solvents $\left(17.06 \mathrm{~g} \mathrm{~L}^{-1}\right)$ and organic acids $\left(7.47 \mathrm{~g} \mathrm{~L}^{-1}\right)$ were still coproduced via the proposed strategy even under the environment of five phenolics existence. It is important to mention that

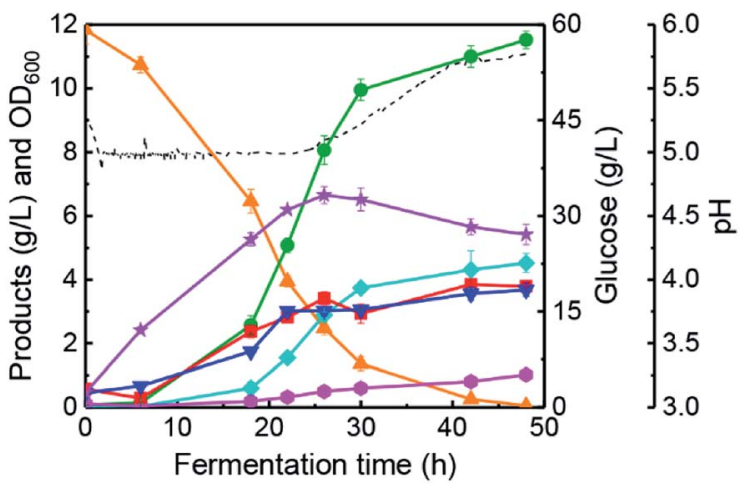

Fig. 6 The time courses of butanol fermentation with five phenolics addition $\left(0.2 \mathrm{~g} \mathrm{~L}^{-1}\right)$ under the $\mathrm{pH}$-control strategy. •: butanol; acetone; ethanol; $\mathbf{\square}$ : acetate; $\mathbf{\nabla}$ : butyrate; $\star$ : $\mathrm{OD}_{600} ; \boldsymbol{\Delta}$ : glucose; broken line: $\mathrm{pH}$. The adding amount of phenolics was $0.04 \mathrm{~g} \mathrm{~L}^{-1}$ vanillin, $0.04 \mathrm{~g} \mathrm{~L}^{-1}$ vanillic acid, $0.04 \mathrm{~g} \mathrm{~L}^{-1} p$-hydroxybenzaldehyde, $0.04 \mathrm{~g} \mathrm{~L}^{-1} p$-hydroxybenzoic acid, and $0.04 \mathrm{~g} \mathrm{~L}^{-1}$ ferulic acid. combined phenolics addition might have synergistic effects on the metabolism of C. acetobutylicum ATCC 824, and the speculation will be verified and investigated in the upcoming works.

There would be a concern about the feasibility of the proposed fermentation strategy for fine chemicals production. One possible approach for butyl butyrate production could be achieved by adding butyrate (that is produced by butyrate fermentation with $C$. tyrobutyricum) after butanol fermentation instead of modifying ABE fermentation by addition ligninderived phenolics. However, the titre of butyrate produced by microbial fermentation is generally in the range of 20-50 g $\mathrm{L}^{-1},{ }^{11}$ and butanol titre in ABE fermentation is generally $<20 \mathrm{~g}$ $\mathrm{L}^{-1}$. If adding butyrate after butanol fermentation to produce butyl butyrate, the overall productivity of bioreactor will be low, and the purification cost of butyrate will also deteriorate the process economics. When using the fermentation strategy proposed in this study for fine chemicals production, the butanol fermentation would not be ended because the concentration of butanol is lower than the tolerance threshold value. Consequently, we believed that the strategy of ligninderived phenolics addition would show a great potential for efficient production of butyl butyrate or other fine chemicals with an economic approach.

\section{Conclusions}

Organic acids in conventional butanol fermentation are regarded as the main by-products, but they can be used for valueadded chemicals production. In this work, we investigated the effects of lignin-derived phenolics addition on butanol fermentation for the co-production of solvents and organic acids. A novel fermentation strategy of phenolics addition with $\mathrm{pH}$-control was proposed in a $5 \mathrm{~L}$ anaerobic fermenter, and results indicated that the concentration of solvents and organic acids reached in the ranges of 11.77-13.85 $\mathrm{g} \mathrm{L}^{-1}$ (vs. $13.69 \mathrm{~g} \mathrm{~L}^{-1}$ control) and 9.21-12.57 $\mathrm{g} \mathrm{L}^{-1}$ (vs. $6.38 \mathrm{~g} \mathrm{~L}^{-1}$ control), respectively. Furthermore, the butyrate/butanol ratio reached the highest level of $0.80 \mathrm{~g} \mathrm{~g}^{-1}$ with vanillin/vanillic acid co-addition.

\section{Conflicts of interest}

The authors declare that there is no conflict of interest.

\section{Acknowledgements}

This work was supported by the National Natural Science Foundation of China (21808075), the Natural Science Foundation of Jiangsu Province (BK20170459, and BK20170458), the National Natural Science Foundation of China (21706088), and the Natural Science Foundation of the Higher Education Institutions of Jiangsu Province (16KJB530001).

\section{References}

1 J. C. Liao, L. Mi, S. Pontrelli and S. Luo, Nat. Rev. Microbiol., 2016, 14, 288-304.

2 P. Dürre, Biotechnol. J., 2007, 2, 1525-1534. 
3 L. D. Gottumukkala, K. Haigh and J. Görgens, Renewable Sustainable Energy Rev., 2017, 76, 963-973.

4 S. Y. Lee, J. H. Park, S. H. Jang, L. K. Nielsen, J. Kim and K. S. Jung, Biotechnol. Bioeng., 2008, 101, 209-228.

5 J. Zheng, Y. Tashiro, Q. Wang and K. Sonomoto, J. Biosci. Bioeng., 2015, 119, 1-9.

6 S. H. Lee, E. J. Yun, J. Kim, S. J. Lee, Y. Um and K. H. Kim, Appl. Microbiol. Biotechnol., 2016, 100, 8255-8271.

7 C. Xue, X. Zhao, C. Liu, L. Chen and F. Bai, Biotechnol. Adv., 2013, 31, 1575-1584.

8 Y. S. Jang, A. Malaviya, C. Cho, J. Lee and S. Y. Lee, Bioresour. Technol., 2012, 123, 653-663.

9 L. Q. Ji, Renewable Sustainable Energy Rev., 2015, 44, 561-575.

10 L. J. Jönsson and C. Martín, Bioresour. Technol., 2016, 199, 103-112.

11 H. Luo, R. Yang, Y. Zhao, Z. Wang, Z. Liu, M. Huang and Q. Zeng, Bioresour. Technol., 2018, 253, 343-354.

12 S. Maiti, G. Gallastegui, S. J. Sarma, S. K. Brar, Y. L. Bihan, P. Drogui, G. Buelna and M. Verma, Biomass Bioenergy, 2016, 94, 187-200.

13 N. R. Baral and A. Shah, Appl. Microbiol. Biotechnol., 2014, 98, 9151-9172.

14 T. Ezeji, N. Qureshi and H. P. Blaschek, Biotechnol. Bioeng., 2007, 97, 1460-1469.

15 D. Yao, S. Dong, P. Wang, T. Chen, J. Wang, Z. B. Yue and Y. Wang, Fuel, 2017, 208, 549-557.

16 P. Torre, B. Aliakbarian, B. Rivas, J. M. Domínguez and A. Converti, Biochem. Eng. J., 2008, 40, 500-506.

17 J. Liu, Q. Lin, X. Chai, Y. Luo and T. Guo, Microb. Cell Fact., 2018, 17, 35.

18 W. H. Chen and Y. R. Zeng, Bioresour. Technol., 2018, 261, 44-51.

19 O. Ibraheem and B. K. Ndimba, Int. J. Biol. Sci., 2013, 9, 598612.

20 S. O. Seo, Y. Wang, T. Lu, Y. S. Jin and H. P. Blaschek, Biotechnol. Bioeng., 2017, 114, 106-112.

21 C. van den Berg, A. S. Heeres, L. A. M. van der Wielen and A. J. J. Straathof, Biotechnol. Bioeng., 2013, 110, 137-142.

22 F. Xin, A. Basu, K. L. Yang and J. He, Bioresour. Technol., 2016, 202, 214-219.

23 H. J. Noh, J. E. Woo, S. Y. Lee and Y. S. Jang, Appl. Microbiol. Biotechnol., 2018, 102, 8319-8327.

24 C. Chen, H. Chen, G. Sun, J. Cai, Y. Zhen, D. Cai, P. Qin, B. Chen and T. Tan, Process Biochem., 2018, 71, 12-17.

25 D. Cai, Z. Dong, J. Han, H. Yu, Y. Wang, P. Qin, Z. Wang and T. Tan, Green Chem., 2016, 18, 1377-1386.
26 F. Xin, W. Dong, Y. Jiang, J. Ma, W. Zhang, H. Wu, M. Zhang and M. Jiang, Crit. Rev. Biotechnol., 2018, 38, 529-540.

27 H. Luo, L. Ge, J. Zhang, J. Ding, R. Chen and Z. Shi, Bioresour. Technol., 2016, 200, 111-120.

28 H. Luo, J. Zhang, H. Wang, R. Chen, Z. Shi, X. Li and J. Ding, Biochem. Eng. J., 2017, 118, 132-142.

29 C. Cho and S. Y. Lee, Biotechnol. Bioeng., 2017, 114, 374-383.

30 X. Li, Z. Li, J. Zheng, Z. Shi and L. Li, Bioresour. Technol., 2012, 125, 43-51.

31 Y. Liu, Y. Geng, Q. Zhou and W. Yuan, BioResources, 2018, 13, 5850-5861.

32 J. Liu, Z. Liu, X. Chai, Y. Luo, T. Guo and H. Ying, Process Biochem., 2018, 68, 43-52.

33 H. Luo, Q. Zeng, S. Han, Z. Wang, Q. Dong, Y. Bi and Y. Zhao, World J. Microbiol. Biotechnol., 2017, 33, 76.

34 S. Wang, Y. Zhang, H. Dong, S. Mao, Y. Zhu, R. Wang, G. Luan and Y. Li, Appl. Environ. Microbiol., 2011, 77, 16741680.

35 T. Ezeji, C. Milne, N. D. Price and H. P. Blaschek, Appl. Microbiol. Biotechnol., 2010, 85, 1697-1712.

36 B. M. Ennis and I. S. Maddox, Biotechnol. Bioeng., 1987, 29, 329-334.

37 M. Jiang, J. Chen, A. He, H. Wu, X. Kong, J. Liu, C. Yin, W. Chen and P. Chen, Process Biochem., 2014, 49, 1238-1244.

38 M. Gao, Y. Tashiro, Q. Wang, K. Sakai and K. Sonomoto, J. Biosci. Bioeng., 2016, 122, 176-182.

39 E. C. van der Pol, R. R. Bakker, P. Baets and G. Eggink, Appl. Microbiol. Biotechnol., 2014, 98, 9579-9593.

40 C. Bellido, S. Lucas, G. González-Benito, M. T. García-Cubero and M. Coca, Food Bioprod. Process., 2018, 108, 117-125.

41 S. A. Nicolaou, S. M. Gaida and E. T. Papoutsakis, Metab. Eng., 2010, 12, 307-331.

42 S. Kim, Y. S. Jang, S. C. Ha, J. W. Ahn, E. J. Kim, J. H. Lim, C. Cho, Y. S. Ryu, S. K. Lee and S. Y. Lee, Nat. Commun., 2015, 6, 8410.

43 N. Qureshi, B. C. Saha, R. E. Hector, B. Dien, S. Hughes, S. Liu, L. Iten, M. J. Bowman, G. Sarath and M. A. Cotta, Biomass Bioenergy, 2010, 34, 566-571.

44 N. Qureshi, B. C. Saha and M. A. Cotta, Biomass Bioenergy, 2008, 32, 168-175.

45 D. H. Cho, J. L. Yun, Y. Um, B. I. Sang and H. K. Yong, Appl. Microbiol. Biotechnol., 2009, 83, 1035-1043.

46 Z. T. Zhang, S. Taylor and Y. Wang, Biotechnol. Bioeng., 2017, 114, 1428-1437.

47 C. Chen, D. Cai, P. Qin, B. Chen, Z. Wang and T. Tan, Bioresour. Technol., 2018, 257, 217-222. 